\title{
Importance of primary metabolites in canola in mediating interactions between a specialist leaf-feeding insect and its specialist solitary endoparasitoid
}

\author{
Mahmoud Soufbaf • Yaghoub Fathipour • \\ Myron P. Zalucki • Cang Hui
}

Received: 5 October 2011/Accepted: 3 January 2012/Published online: 10 February 2012

(C) Springer Science+Business Media B.V. 2012

\begin{abstract}
The role of primary plant chemistry on trophic interactions is not well studied. We examined the effect of primary plant metabolites, focusing on nitrogen, on several biological indices of second and third trophic level insects in a model tritrophic system, consisting of two strains of the crucifer, Brassica napus (canola) $\left(\mathrm{SLM}_{046}\right.$ and $\mathrm{RGS}_{003}$ ), the specialist insect herbivore Plutella xylostella (L.) (Lepidoptera: Plutellidae), and its specialist koinobiont larval-pupal parasitoid Diadegma semiclausum (Hellén) (Hymenoptera: Ichneumonidae). In particular, we measured relative growth rate of the herbivore in relation to an index for plant quality (nitrogen content of leaf tissues), developmental time of the herbivore (sum of second, third, and fourth larval instars durations), and intrinsic rate of increase $\left(r_{m}\right)$ of the herbivore and the parasitoid. Tritrophic studies were conducted on development, survivorship curve analysis, reproductive potential, life history, parasitism, and several other fitness correlates of the parasitoid. The life table parameters of $D$. semiclausum were determined under laboratory conditions. The intrinsic rate of increase $\left(r_{m}\right)$ of the parasitoid was significantly higher on
\end{abstract}

Handling Editor: Robert Glinwood.

M. Soufbaf · Y. Fathipour ( $\bowtie)$

Department of Entomology, Faculty of Agriculture, Tarbiat

Modares University, P.O. Box 14115-336, Tehran, Iran

e-mail: fathi@modares.ac.ir

M. P. Zalucki

School of Biological Sciences, The University of Queensland,

St. Lucia, QLD 4072, Australia

C. Hui

Department of Botany and Zoology, Center for Invasion

Biology, University of Stellenbosch, Matieland 7602,

South Africa
$\mathrm{RGS}_{003}$ than $\mathrm{SLM}_{046}$. In this tritrophic model, the results indicated that the bottom-up direct effect on the herbivore population growth rate was marginally as strong as the direct effect of top-down force due to the parasitoid population growth rate; but it was higher than its indirect counterpoint mediated with the parasitoid population growth rate. Consequently, D. semiclausum performed better on $\mathrm{RGS}_{003}$, which was the most inferior host to $P$. xylostella in comparison with another plant cultivar and had the lowest content of nitrogen in its leaves.

Keywords Plant quality - Insect fitness - Plutella xylostella $\cdot$ Diadegma semiclausum

\section{Introduction}

Plant quality can affect herbivore fitness directly as food of herbivores and indirectly by affecting foraging cues for natural enemies of herbivores (Awmack and Leather 2002; Walker et al. 2008). Bottom-up effect can further extend to the third and even fourth trophic levels (Harvey et al. 2007). For instance, the rate of parasitism in some lepidoptera can vary considerably depending on the plant species on which they are feeding (Hunter 2003; Lill et al. 2002); this is true even when feeding on different cultivars of one plant species in agro-ecosystems (Eigenbrode et al. 1996). Domestication of brassicaceous plants in some cases has reduced the level of secondary plant metabolites in addition to changes in the strength of indirect plant responses (Gols et al. 2008b). For instance, artificial selection in Brassica oleracea (one of the progenitors of $B$. napus) has caused a significant variation in shape and structure of different parts of the plants (Benrey et al. 1998). Artificial selection has also produced different 
concentrations of nitrogen and glucosinolates in several wild and domesticated crucifers (Scriber 1981).

It has been long demonstrated that toxic secondary compounds (allelochemicals) in an herbivore diet may affect their natural enemies' fitness, including development, survival, morphology, and size (Harvey et al. 2007; Ode et al. 2004). This effect of poor-quality plants can thus indirectly lead to poor-quality parasitoids (Hunter and Price 1992; Hunter 2003; Price et al. 1980). However, the strength of this bottom-up force has yet to be measured especially when primary metabolites cascade-up to higher trophic levels.

Much previous research in plant-insect interactions has focused on the role of toxic secondary plant compounds on insect performance; see reviews by Harvey (2005), Ode (2006), and primary studies by Barbosa et al. (1991), Campbell and Duffey (1979), Gols et al. (2008a, b, 2009), Gunasena et al. (1990), Harvey et al. (2003), Kos et al. (2011), Poelman et al. (2009), Soler et al. (2005, 2007); while primary plant metabolites, including nitrogen, which have been shown to strongly affect the feeding and growth of insect herbivores (Johnson 2008; Mattson 1980; Scriber 1979; Smith and Northcott 1951; White 1984) has been paid less attention. Moreover, to manipulate the nitrogen content of plants (i.e., to vary the plants' nutrient quality), studies often apply different levels of synthetic nitrogenous fertilizers; see for example, Aqueel and Leather (2011) and Smith and Northcott (1951). A problem in such studies is that the plant biomass changes as the plants grow faster (Stiling and Moon 2005), so one cannot precisely isolate the effect of plant quality on insect fitness. Here, we selected two Brassica napus (canola) cultivars (SLM $_{046}$ and $\mathrm{RGS}_{003}$ ) to represent high- and low-quality host plants that differ dramatically in nitrogen content and previously were shown to significantly affect the biology and life table parameters of diamondback moth (DBM) (Soufbaf et al. 2010a, b). To quantify the strength of the bottom-up effect, we utilized a tritrophic system consisting of DBM, Plutella xylostella (L.) (Lepidoptera: Plutellidae), as the herbivore which is among the most important pest of cruciferous crops in the world (Talekar and Shelton 1993), and one of its major parasitoids, Diadegma semiclausum (Hellén) (Hymenoptera: Ichneumonidae), an important natural control agent of DBM (Lohr et al. 2007; Talekar and Shelton 1993).

Our objectives were to determine: (1) whether the performance of DBM, measured by its relative growth rate $(R G R)$, the larval development time (sum of the second, third, and fourth larval instars), and larval weight differs when feeding on these two plant cultivars (2) whether the performance of the parasitoid D. semiclausum, quantified by the vital rates potentially affecting its fitness, is also affected by the primary metabolite of plant cultivars on which its' host feeds?, and finally, (3) how does the fitness of both DBM and D. semiclausum correspond to the primary chemistry of their host plant?

\section{Materials and methods}

\section{Study species}

Two cultivated B. napus cultivars, $\mathrm{SLM}_{046}$ and $\mathrm{RGS}_{003}$, were used in the laboratory trials. Seeds were obtained from the Seed and Plant Improvement Institute, Karaj, Iran, and used for raising plants in the greenhouse $\left(27 \pm 5^{\circ} \mathrm{C}, 60 \pm 10 \%\right.$ $\mathrm{RH})$. Plants were raised in a standard potting mix in plastic pots ( $20 \mathrm{~cm}$ height and $15 \mathrm{~cm}$ diameter); 4-5 seeds were planted in each pot, without any fertilizer. Leaves from 4-weak-old plants were used in all trials. To evaluate the nitrogen content of plant leaves, we dried leaves of each plant cultivar at $55^{\circ} \mathrm{C}$ for $12 \mathrm{~h}$ to get the dry weights, and then, the nitrogen content of these dried ground leaves was estimated by the Kjeldahl method (Karla 1998). Three replicates were run for each host plant; dried leaf samples of each plant cultivar were obtained from ten different plants due to variability in nitrogen quality and quantity among individual plants (Mattson 1980).

A colony of DBM was established and maintained in the laboratory on cabbage, B. oleracea var. capitata Linnaeus. DBM larvae and pupae were originally collected from cabbage grown in the horticulture fields of the University of Tehran. The stock culture was maintained for about 2 months in the greenhouse. Sub-colonies were established on the two test plant cultivars separately and maintained in a constant environment at $25 \pm 2{ }^{\circ} \mathrm{C}$ on the respective host plants for more than four generations before the trials. At least 120 moths were used to initiate the colony and 20 wild adult males/females, collected from the field, were added to each colony (stock culture and sub-colonies) weekly.

A potted canola plant with one cohort of 200 early-thirdinstar DBM larvae was placed in a perspex cage $(30 \mathrm{~cm} \times 30 \mathrm{~cm} \times 30 \mathrm{~cm})$ with a muslin sleeve on one side of the cage. Ten pairs of 2-d-old mated D. semiclausum were introduced into the cage. The wasps were provided with a diet of $10 \%$ honey solution. After $24 \mathrm{~h}$, the exposed larvae were removed and placed in ventilated plastic containers $(20 \mathrm{~cm} \times 15 \mathrm{~cm} \times 7 \mathrm{~cm})$. Fresh canola leaves were added until pupation. DBM pupa could not form in case of parasitized larva, so the parasitoid pupae were harvested and put in clean plastic containers for adult emergence. The D. semiclausum culture was established and maintained in a constant environment at $25 \pm 2{ }^{\circ} \mathrm{C}$, and adults of the second generation were used in the experiments. 
The performance of DBM

To calculate the relative growth rate $(R G R)$ of the herbivore, we weighed the larvae every $24 \mathrm{~h}$ and defined $R G R$ as the difference in wet weights (natural log) between first and last time periods divided by measurement times (Johnson and Zalucki 2007; Kogan and Cope 1974):

$R G R=\left(\ln \left(w_{t 1}\right)-\ln \left(w_{t 0}\right)\right) /\left(t_{1}-t_{0}\right)$

The $R G R$ was measured for $\sim 20$ larvae per cultivar. To measure the development times of second, third and fourth larval instars, two cohorts of DBM eggs (50 individual eggs laid on clean plants over a 10-h interval) were reared individually until pupation. Although D. semiclausum can parasitize all four larval stages of DBM (Yang et al. 1993), the first instar would not transfer plant quality to the next trophic level. We thus ignored the duration of the first instar in the analysis. The intrinsic rate of increase in the herbivore $\left(r_{m}\right)$ was estimated using the Jackknife simulation model, well described in Maia et al. (2000).

\section{The performance of $D$. semiclausum}

Estimation of the development time of the parasitoid was conducted in the laboratory $\left(25 \pm 1^{\circ} \mathrm{C}, 55 \pm 5 \% \mathrm{RH}\right)$. Each of the test plants $(\sim 20 \mathrm{~cm}$ in average height with eight leaves) was infested with one cohort of 120 secondinstar DBM larvae obtained from the respective host plant cultivar. The plants were placed individually in wood cages $(120 \mathrm{~cm} \times 80 \mathrm{~cm} \times 80 \mathrm{~cm})$ with a muslin sleeve on all sides of the cage. Ten pairs of 2-d-old mated parasitoids were introduced into the cage through the sleeve and allowed to parasitize hosts. These parasitoids were supplied only with $10 \%$ honey solution with no host before the trial. Twenty-four hours later, the plants were removed from the cages. All exposed DBM larvae from each host plant were removed using a soft camel brush and placed individually in plastic Petri dishes $(8 \mathrm{~cm} \times 1.5 \mathrm{~cm})$ containing a leaf from the respective host plant. The Petri dishes were covered with a lid with a muslin-covered window for ventilation and placed in an incubator (Binder KBWF 720, Germany). The leaves from respective test plants were changed daily until the larvae pupated. Cocoon spinning was recorded as the start of the pupal period. The cocoons were weighed within $24 \mathrm{~h}$ of formation to the nearest $10^{-4} \mathrm{~g}$ using a Sartorius electronic balance (Sartorius GMBH, Göttingen, Germany) and then placed individually in plastic vials for adult emergence. Egg-larval period, pupal period, and survivorship of the immature stages of the parasitoid were recorded. When the wasps emerged, the time of eclosion was recorded. Data for superparasitism and dead larvae were discarded.
To assess the effect of different plant cultivars on the reproductive potential of the parasitoid, 20 newly emerged $D$. semiclausum females from each test plant from each cultivar experiment were placed individually in clean plastic vials $(2.5 \mathrm{~cm} \times 7.5 \mathrm{~cm})$ and paired with males from the same test plant cultivar and left together for $6 \mathrm{~h}$ to ensure mating (most pairs mated in the first few seconds). A leaf from the respective test plant was placed in a ventilated plastic container $(15 \mathrm{~cm}$ diameter and $20 \mathrm{~cm}$ height) and infested with one cohort of 20 early second-instar DBM larvae. To prevent the leaf from wilting, the petiole was wrapped with cotton wool soaked in water. A pair of 1-d-old mated D. semiclausum was placed in the container and allowed to oviposit. After every $24 \mathrm{~h}$, parasitoids were transferred to another plastic container with a leaf infested with a cohort of 20 early second-instar DBM larvae, and the process was repeated until death of last female wasp. The exposed larvae were transferred into ventilated plastic containers $(10 \mathrm{~cm} \times 6.5 \mathrm{~cm})$ lined with tissue paper to absorb excess moisture. Leaves from respective test plants were added as required until the larvae pupated. Cocoons from individual females were placed separately in clean ventilated plastic containers $(5 \mathrm{~cm}$ diameter and $4 \mathrm{~cm}$ height) and observed daily for the emergence of adults. The number of emerged DBM and parasitoids was recorded. After the wasps had emerged, the cocoons were checked and the number that failed to emerge recorded. Following Carey (2001), we calculated the life table parameters: the intrinsic rate of natural increase $\left(r_{m}\right)$, mean generation time $(T)$, finite rate of increase $(\lambda)$, doubling time $(D T)$, and net reproductive rate $\left(R_{O}\right)$.

To calculate successful daily percent parasitism, we used the following equation:

Successful Parasitism $(\%)=\left(P_{p} / L_{h}\right) \times 100$,

where $P_{p}$ stands for numbers of parasitoid pupa that developed successfully, and $L_{h}$ is total number of DBM larva released daily to each container.

To assess the effect of different plant cultivars on the body size of the parasitoid, 20 newly emerged male and female parasitoids from each test plant cultivar were killed by placing them in a vial containing $70 \%$ alcohol. The left forewing and left hind tibia were removed using a pair of forceps under a dissecting microscope. The forewing and hind tibia were placed on a microscope slide using a soft camel hair brush and the wing spread in a drop of alcohol. The lengths were measured to the nearest $10^{-2} \mathrm{~mm}$ using a graticule fitted on the dissecting microscope.

Statistical analyses

All data obtained from measurements on two plant cultivars were subjected to Kolmogorov-Smirnov test for normality before analysis, and all pair-wise comparisons were done using Student's $t$-test. The data on fertility were 
subjected to square root transformation before analysis, and the data on daily parasitism rate and nitrogen contents were subjected to $\log$ transformation before analysis. The effect of host plant on the survival of herbivore and parasitoid larvae during the development period was tested using linear regression, and the homogeneity of parasitoid survivorship on the two plant cultivars was tested by the logrank test (Rosner 2000) (PROC LIFETEST, SAS 2003). Values of $1-l_{x}$ in the age class of $x$ were used as the mortality on each cultivar in the LIFETEST program. The data on daily parasitism throughout parasitoid age were analyzed using univariate General Linear Model (GLM) to determine the effects of plant cultivar, parasitoid age, and their interactions on daily parasitism (PROC GLM, SAS 2003), and means were compared by Tukey's test at $P<0.05$ significance level. The life table parameters for the parasitoid were estimated by the Jackknife simulation method (Meyer et al. 1986), and Jackknife pseudo values were subjected to Student's $t$-test for pair-wise comparisons. Pair-wise correlations of pupal weight, fertility, forewing length, and hind tibia were conducted using Pearson product-moment coefficient (r) with a significance level of $\alpha=0.01$, to identify relationships between structural measurement and weight of parasitoid cocoons. Direct and indirect effects of nitrogen content of leaves on development time of both herbivore and parasitoid, $R G R$ of herbivore, and the intrinsic rate of natural increase $r_{m}$ in both herbivore and parasitoid were assessed using path analysis after Bryman and Cramer (2002). Data transformations, Student's $t$-tests, regressions, path, and Pearson correlation analyses were performed using SPSS 16 (SPSS 2008).

\section{Results}

Plant cultivar quality

Nitrogen contents of leaves, as an index for plant quality, were significantly different between the two experimental plant cultivars (5.1 and $1.6 \%$ for $\mathrm{SLM}_{046}$ and $\mathrm{RGS}_{003}$, respectively). There was $350 \%$ more nitrogen in $\mathrm{SLM}_{046}$ than in $\mathrm{RGS}_{003}(\mathrm{~T}=-40.86$, df $=2, P=0.001)$.

Effect of plant cultivars on mass growth and development time of DBM

Relative growth rate $(R G R)$ of DBM differed between two plant cultivars; for individuals reared on $\mathrm{RGS}_{003}$, the $R G R$ was higher compared with those on $\operatorname{SLM}_{046}$ (Table 1). Accordingly, weight of larvae at the 4th instar on $\mathrm{RGS}_{003}$ was higher than on $\mathrm{SLM}_{046}$. Larval development time (time in second + third + fourth instars) differed between the two plant cultivars (Table 1).

Effect of plant cultivars on the fitness of $D$. semiclausum

\section{Fertility, development, parasitism, and survivorship}

The total number of offspring produced by parasitoids was significantly higher on $\mathrm{RGS}_{003}$ than $\mathrm{SLM}_{046}$ (Table 1), but the overall parasitism rate on the two host plant was not significantly different. The female longevity with host and food was significantly greater on $\mathrm{RGS}_{003}$ than on $\mathrm{SLM}_{046}$ (Table 1), which probably accounts for the greater number of offspring produced. Data on daily parasitism showed significant differences between the two cultivars and among parasitoid ages (Table 2). The highest daily parasitism was observed on $\mathrm{RGS}_{003}$ and on 2 nd day as $57.5 \pm 4.7 \%$ and showed significant difference with daily percent parasitism on 4 th day $(43.5 \pm 12.7 \%)$. Also, there was a significant difference between parasitism on days 1 and 4 . Daily percent parasitism on 1 st day was $2.82 \%$ more than its value on 4 th day. The age-specific survivorship $\left(l_{x}\right)$ at age of adult emergence of $D$. semiclausum on $\mathrm{RGS}_{003}$ and $\mathrm{SLM}_{046}$ was 0.82 and 0.69 , respectively. Regression analysis showed that larval survivorship declines with a steeper slope in $\mathrm{SLM}_{046}$, survival $=0.989-0.0289 \quad$ age $\quad\left(\mathrm{R}^{2}=95 \%, \quad \mathrm{p}_{\text {inter- }}\right.$ cept $=0.000$ ) than in RGS003, that is, survival $=1.05$ 0.0166 age $\left(\mathrm{R}^{2}=87 \%\right.$, $\left.\mathrm{p}_{\text {intercept }}=0.000\right)$. Log-rank test showed that the survival curve patterns were the same for parasitoids on the two plant cultivars, Deevey's curve type I (Deevey 1947) $\left(\chi^{2}=3.0248, \mathrm{df}=1, P=0.0826\right)$ (Fig. 1). The pupal period of the parasitoid was significantly longer on $\mathrm{SLM}_{046}$ (Table 1).

\section{Morphological structures}

Forewing length varied significantly between females and males. The lowest and highest values were observed on $\mathrm{SLM}_{046}$ and $\mathrm{RGS}_{003}$, respectively (Table 1). Forewing lengths in females varied from 2.7 to $3.67 \mathrm{~mm}$ and from 2.87 to $3.4 \mathrm{~mm}$ in males on $\mathrm{SLM}_{046}$; these size ranges for females on $\mathrm{RGS}_{003}$ were 3.025-3.925 mm and 3-3.9 for males. The lowest and highest pupal weights and lowest and highest adult weights of D. semiclausum were observed on $\mathrm{SLM}_{046}$ and $\mathrm{RGS}_{003}$, respectively (Table 1). Pupal weights varied from 0.0018 to $0.0039 \mathrm{~g}$ and from 0.0020 to $0.0053 \mathrm{~g}$ on $\mathrm{SLM}_{046}$ and $\mathrm{RGS}_{003}$, respectively. Accordingly, adult body weights varied from 0.0011 to $0.0066 \mathrm{~g}$ and from 0.0008 to $0.0065 \mathrm{~g}$ on $\mathrm{SLM}_{046}$ and $\mathrm{RGS}_{003}$, respectively. There were no significant differences in tibia lengths. Correlations showed significant inverse relationships between pupal weight and female tibia 
Table 1 Life history traits of herbivore (Plutella xylostella) (DBM) and its larval parasitoid Diadegma semiclausum on two cultivated canola cultivars

\begin{tabular}{|c|c|c|c|c|}
\hline Plant cultivar & $\mathrm{SLM}_{046}$ & $\mathrm{RGS}_{003}$ & $d f$ & $\mathrm{~T}$ \\
\hline \multicolumn{5}{|l|}{ Insect performance } \\
\hline \multicolumn{5}{|l|}{ DBM } \\
\hline$R G R\left(\mathrm{mg} \mathrm{mg}^{-1} \mathrm{~d}^{-1}\right)$ & $0.429 \pm 0.024$ & $0.509 \pm 0.027$ & 44 & $2.21^{*}$ \\
\hline Larval development time (2nd, 3rd, and 4th instars) (days) & $5.64 \pm 0.14$ & $6.54 \pm 0.13$ & 84 & $4.63^{* * *}$ \\
\hline Larval weight in last instar (4th) $(\mathrm{g})$ & $0.005 \pm 0.00026$ & $0.006 \pm 0.00027$ & 40 & $-2.32^{*}$ \\
\hline \multicolumn{5}{|l|}{ D. semiclausum } \\
\hline Pupal period (days) & $6.51 \pm 0.09$ & $6.24 \pm 0.09$ & 70 & $-2.18^{*}$ \\
\hline Number of offsprings & $15.90 \pm 1.9$ & $22.30 \pm 2.2$ & 17 & $2.18^{*}$ \\
\hline Female longevity with host (with parasitism activity) & $3.00 \pm 0.24$ & $5.40 \pm 0.91$ & 10 & $2.56^{*}$ \\
\hline Pupal weight (mg) & $2.54 \pm 0.000$ & $3.24 \pm 0.000$ & 167 & $6.03^{* * *}$ \\
\hline Adult body weight (mg) & $2.38 \pm 0.000$ & $3.22 \pm 0.000$ & 63 & $2.44^{*}$ \\
\hline \multicolumn{5}{|l|}{ Forewing length (mm) } \\
\hline Female & $3.11 \pm 0.05$ & $3.49 \pm 0.09$ & 21 & $-3.42^{* * *}$ \\
\hline Male & $3.05 \pm 0.03$ & $3.31 \pm 0.07$ & 19 & $-3.08^{* * *}$ \\
\hline Net reproductive rate $\left(R_{O}\right)^{\mathrm{a}}$ & $5.56 \pm 0.67$ & $7.62 \pm 0.84$ & - & ns \\
\hline Finite rate of increase $(\lambda)$ & $1.16 \pm 0.00$ & $1.21 \pm 0.16$ & 12 & $2.69^{*}$ \\
\hline Intrinsic rate of increase $\left(r_{m}\right)$ & $0.147 \pm 0.07$ & $0.188 \pm 0.01$ & 13 & $2.72^{*}$ \\
\hline Mean generation time $(T)$ & $20.25 \pm 5.43$ & $14.00 \pm 1.75$ & - & ns \\
\hline Doubling time $(D T)$ & $4.67 \pm 0.18$ & $3.66 \pm 0.27$ & 15 & $-3.06^{* *}$ \\
\hline
\end{tabular}

Population growth parameters of Diadegma semiclausum obtained using Jackknife simulation method on canola cultivars

The values are Means \pm SE of insect performances measurements after Student's $t$-test

${ }^{a}$ This parameter showed difference between cultivars at $P=0.07 .{ }^{*} P<0.05,{ }^{* *} P<0.01,{ }^{* * * *} P<0.001$, and ${ }^{\mathrm{ns}} P>0.05$

Table 2 Analysis from the daily percent parasitism of Diadegma semiclausum, parasitoid of Plutella xylostella, on two cultivated canola cultivars

\begin{tabular}{llrr}
\hline Source & Type III sum of squares & $d f$ & F \\
\hline Model & 9.83283772 & 48 & $3.40^{* * *}$ \\
Age & 2.84042867 & 4 & $11.78^{* * *}$ \\
Cultivar & 0.78640240 & 1 & $13.04^{* *}$ \\
Replication & 2.14410660 & 9 & $3.95^{* *}$ \\
Age $\times$ cultivar & 1.05702778 & 3 & $5.84^{* *}$ \\
Replication $\times$ age & 4.84948351 & 23 & $3.50^{* *}$ \\
Error & 0.90440362 & 15 & \\
\hline
\end{tabular}

A linear model approach was used to assay changes in percent parasitism between cultivars with age of parasitoid

The only significant main effects and their interactions were showed here. ${ }^{*} P<0.05,{ }^{* *} P<0.01,{ }^{* * *} P<0.001$, and ${ }^{\text {ns }} P>0.05$

lengths on the two plant cultivar $(\mathrm{r}=-0.642, P<0.01$ on $\mathrm{SLM}_{046} ; \mathrm{r}=-0.598, P<0.05$ on $\left.\mathrm{RGS}_{003}\right)$, and positive correlation between pupal weight and female forewing length for parasitoids reared on $\mathrm{RGS}_{003}(\mathrm{r}=0.712$, $P<0.01)$.

\section{Life table parameters}

The intrinsic rate of increase, $r_{m}$, in D. semiclausum was significantly different between cultivars as the cohort reared on $\mathrm{RGS}_{003}$ had the higher $r_{m}$ (Table 1), but the net reproductive rate $\left(R_{O}\right)$ and mean generation time $(T)$ were not significantly different between cultivars. The cohort reared on $\mathrm{RGS}_{003}$ had the smallest doubling time $(D T)$ and those on $\mathrm{SLM}_{046}$ had the smallest finite rate of increase $(\lambda)$ (Table 1).

Relationship between plant quality and insect fitness

The total standardized direct effect of nitrogen on parasitoid $r_{m}$ was negative and strong, more powerful than the standardized indirect effect mediated with $R G R$ 


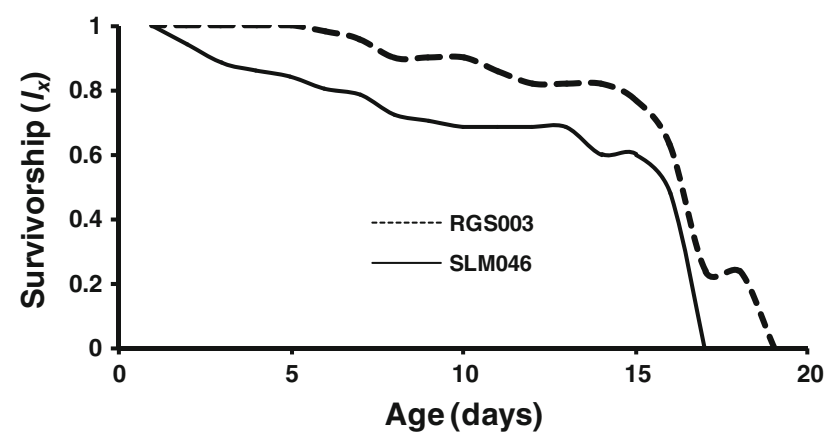

Fig. 1 Survivorship patterns of Diadegma semiclausum reared on two plant cultivars under laboratory conditions. This figure is prepared using Microsoft Office Excel 2007, copied and then pasted as picture (enhanced metafile) to this file

(Nitrogen $\rightarrow R G R \rightarrow$ Parasitoid $r_{m}, \quad \beta=-0.196$ ). The direct effect of nitrogen on the herbivore $r_{m}$ was positive and stronger than its effect on parasitoid $r_{m}$ (Fig. 2). The indirect path Nitrogen $\rightarrow R G R \rightarrow$ Herbivore $r_{m}$ was relatively effective $(\beta=+0.307)$, but lower than its direct counterpoint. There was a negative effect of herbivore development time on parasitoid development time; but the effect in question on parasitoid $r_{m}$ was weak. The effect of $R G R$ on herbivore $r_{m}$ was negative and relatively strong. The direct effect defined as Nitrogen $\rightarrow$ Herbivore $r_{m}$ was the strongest bottom-up force at the first place and Nitrogen $\rightarrow$ Parasitoid $r_{m}$ at the second place as demonstrated here. As a strong top-down force, there was a direct negative effect of parasitoid $r_{m}$ on herbivore $r_{m}$ (Fig. 2, Table 3).

\section{Discussion}

There are many studies regarding the development of fitness strategies in both herbivore and parasitoid but most of them have focused on secondary chemistry of plants, while ignoring the potentially opposite (or countering) effect of primary plant metabolites. Furthermore, many studies are available which examine the effects of synthetic nitrogenous fertilizers as an index for plant quality on insect fitness. Here, we compare our results with some of these studies to compare primary and secondary metabolites' effects on the performance of insects in the second and third trophic level and, to explore the potential differences between natural plant quality and chemically enhanced plant quality using fertilizers.

\section{DBM performance}

DBMs grew slower (lower $R G R$ ), completed development in a shorter time at a smaller weight on $\mathrm{SLM}_{046}$, which is the most suitable host plant for DBM, in terms of $r_{m}$ (Soufbaf et al. 2010a). This cultivar has a significantly higher value of nitrogen in its leaves than another host plant, $\mathrm{RGS}_{003}$. On the latter, development time for DBM

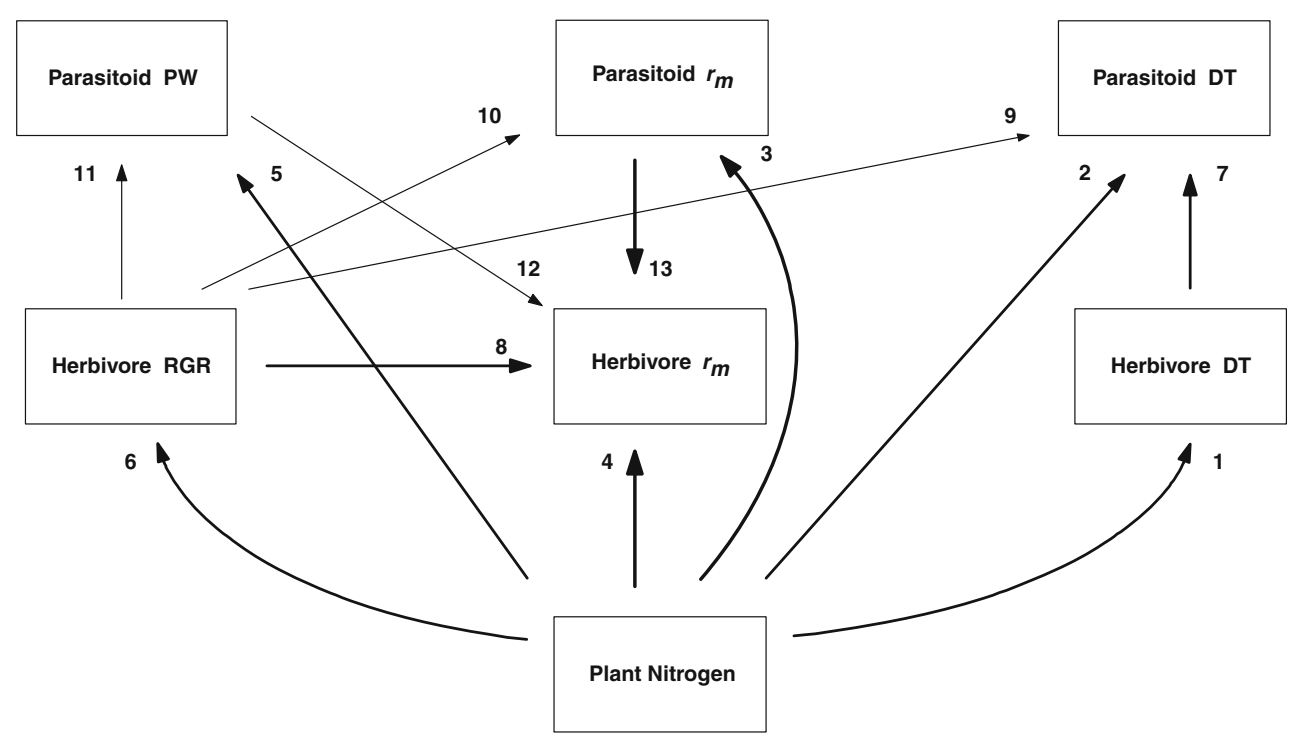

Fig. 2 Output diagram of causal relationships in the plant nitrogen survey on the fitness of second (DBM), and third (Diadegma semiclausum) trophic levels after path analysis. Arrows represent standardized direct and indirect effects of trophic levels components on each other. Thickness of arrows is proportional to the size of the effect. Path coefficients $(\beta)$, errors $\left(\mathrm{e}=1-\mathrm{R}^{2}\right)$, and $P$-values represented in Table 3 (the numbers close to the head of arrows represent the path number). DT represents larval development time (2nd +3 rd +4 th instars) for herbivore and egg + larvae + pupa duration for parasitoid, PW represents pupal weight. Upward and downward arrows represent bottom-up and top-down forces directions in the tritrophic model. This figure is prepared using Flow Charting 6, copied and then pasted as picture (enhanced metafile) to this file 
Table 3 Standardized path coefficients $(\beta)$, errors (e $=1-\mathrm{R}^{2}$ ), and $P$-values of causal relationships in the plant nitrogen survey on the fitness of second (DBM), and third (Diadegma semiclausum) trophic levels after path analysis

\begin{tabular}{lllll}
\hline Path & $\beta$ & $\mathrm{e}=\left(1-\mathrm{R}^{2}\right)$ & $F$ & $P$ value \\
\hline 1 & -0.476 & 0.773 & 1.174 & 0.348 \\
2 & +0.431 & 0.815 & 0.910 & 0.394 \\
3 & -0.895 & 0.199 & 16.052 & 0.016 \\
4 & 0.08 & 46.047 & 0.002 \\
5 & +0.959 & 0.755 & 1.295 & 0.319 \\
6 & -0.495 & 0.563 & 3.110 & 0.153 \\
7 & -0.661 & 0.908 & 7.162 & 0.009 \\
8 & -0.303 & 0.784 & 7.983 & 0.008 \\
9 & -0.465 & 0.984 & 0.760 & 0.388 \\
10 & -0.126 & 0.913 & 1.725 & 0.206 \\
11 & +0.296 & 0.943 & 2.114 & 0.155 \\
12 & +0.239 & 0.899 & 3.267 & 0.081 \\
13 & -0.318 & 0.079 & 46.716 & 0.002 \\
\hline
\end{tabular}

was longer, but larvae gained weight faster (high $R G R$ ) and were heavier at the end of the larval period. One interpretation could be related to the high level of nitrogen available in the plant cultivar $\mathrm{SLM}_{046}$ and so DBM satisfies nitrogen needs with feeding in shorter periods and a lower growth rate. Larvae on the low-nitrogen plant has to feed longer to gain the same or similar amount of nitrogen and end up larger but not necessarily fitter; see Raubenheimer and Simpson (1997) on the C/N balance hypothesis. Using a different method to define $R G R$, Coley et al. (2006) showed that caterpillar's $R G R$ was faster on young leaves, which had higher values of nitrogen than the older leaves. Contrary to our findings, many workers have found that caterpillars developed more slowly on low-nitrogen plants than on high-nitrogen plants (e.g., Loader and Damman 1991; Lou and Baldwin 2004). However, there are reports that larval performance (e.g., larval growth) is relatively independent of plant nitrogen (Karowe and Martin 1989; Prudic et al. 2005). We observed a negative and relatively strong effect of $R G R$ on the herbivore $r_{m}$; as an implicit result, higher population growth rates could not have resulted from higher $R G R$ s.

High level of secondary metabolites, glucosinolate (GS) as the major secondary metabolite in crucifers, reduce the performance of DBM (Gols et al. 2008a; Li et al. 2000), and this reduction is usually less pronounced than in generalist herbivores. Gols et al. (2008a) reported that DBM developed most poorly on the wild population of Brassica which had higher values of GS in their leaf tissues. We encountered a similar scenario, as nitrogen showed a negative and relatively strong effect on $R G R(\beta=-0.661$, $P=0.153)$. This negative effect is confirmed according to slower $R G R$ on $\mathrm{SLM}_{046}$, which had the higher contents of nitrogen in its leaves than the other plant cultivar. Low nitrogen results in a total consumption increase through prolonged developments of herbivores (Coley et al. 2006; Mattson 1980), as we found.

Agrawal (2004) suggested that nitrogen content is a good predictor of $r_{m}$, which will have a strong influence on the population dynamics of herbivores, and our result supports this suggestion. Also, larval development time (feeding window) of herbivores could be a good predictor of parasitoid development time in the current study. A positive causal relationship between nitrogen and intrinsic growth rate of herbivore was observed, which is in spite of Johnson (2008) who reported negative correlations between leaf nitrogen and herbivore $r_{m}$, but is similar to many studies, that report a positive relationship (e.g., Agrawal 2004, Aqueel and Leather 2011, Winter and Rostás 2010).

\section{Parasitoid performance}

Immature survival of parasitoid showed faster declines on $\mathrm{SLM}_{046}$ than on the other plant cultivars. Despite our result, some workers report that immature parasitoid survival was higher on plants with higher nitrogen (fertilizer), which DBM fed on (e.g., Sarfraz et al. 2009). Winter and Rostás (2010) working on soybean-Spodoptera frugiperda-Cotesia marginiventris system, reported similar findings to ours for parasitoid pupal weight, development time, and longevity; although they used synthetic $\mathrm{N}$ fertilizers in plant cultures. Coley et al. (2006) suggested that species feeding on mature leaves (with lower nitrogen contents) were the most defended against natural enemy (ants). Nitrogen had a strong negative effect on parasitoid $r_{m}$; accordingly, $\mathrm{RGS}_{003}$ that had lower values of nitrogen supported fitter parasitoids in our system. Despite our results, there is a positive relationship between nitrogenous fertilizer applications and parasitoid abundance (De Kraker 
et al. 2000; Loader and Damman 1991). We found lower progeny and $r_{m}$ of parasitoid when its host was reared on the plant cultivar that contained a higher level of nitrogen. However, it is frequently reported that performance of parasitoids declined when caterpillars fed on plants raised in nitrogen-poor cultures (e.g., Winter and Rostás 2010).

Gols et al. (2008a; 2009) examining the effect of plant populations with different GS values on parasitoid performance showed that $D$. semiclausum developed more slowly on the cultivated and wild populations of Brassica than on the feral population, while plant population had no significant effect on the survival rates of the parasitoid. However, parasitoid development time did not differ significantly between plant cultivars in our study (data not shown), while survival of immature parasitoids declined faster on the plant cultivar with higher value of nitrogen. Gols et al. (2008b) showed that development time and adult body mass in Cotesia glomerata did not vary significantly with plant species, while adults and pupa of parasitoid were heavier on $\mathrm{RGS}_{003}$ (with lower level of nitrogen) than on another cultivar in the current study.

Our results on the performance of herbivore and its parasitoid under the effect of nitrogen differ from many studies that have examined the effect of secondary plant metabolites on herbivore and its parasitoid performance. We found that performance of DBM increased on the plant cultivar that had a higher content of nitrogen in its leaf tissues, but the story was reverse for parasitoid, as the most fitness correlates of $D$. semiclausum were higher when its host reared on the plant cultivar with lower content of nitrogen. Most often, GSs enhanced the parasioids performance in different ways, but the herbivore performance under GSs effects showed more inconsistent results (see above).

\section{Applied implications and study concerns}

We observed a significant effect of both plant cultivar and parasitoid age on daily percent parasitism, which is similar to many other studies (e.g., Moreau et al. 2009). The highest daily percent parasitism occurred on the second day of parasitism on $\mathrm{RGS}_{003}$, which was reported as the most inferior host plant for DBM (Soufbaf et al. 2010a, b), and had the lowest nitrogen content in the current study. Moreover, there was a strong negative and significant effect of nitrogen on the parasitoid growth rate. Host plant resistance and biological control with parasitoids are two important tactics, which are utilized in many management programs (Ode 2006); interestingly, $\mathrm{RGS}_{003}$ showed both compatibility to parasitoid and unsuitability to herbivores in our artificial system. In general, it is thought that plant resistance and biological control are incompatible. So, using some plant cultivars like $\mathrm{RGS}_{003}$, which naturally represent low qualities for the herbivore and inversely improve the parasitoid fitness could have implications for managers to achieve safer agro-ecosystems and potentially lessen management costs. We have yet to address the question of how plant palatability and yield correlate with primary metabolites in plant cultivars, and we leave this interesting question for future research.

Even though nitrogen is one of the most important plant components that strongly affect insect fitness, DBM has shown to be influenced considerably by sulfur contents in leaf tissues of its host plant. Gupta and Thorsteinson (1960) argued that sulfur could enhance the attractiveness of host plant as oviposition substrate for DBM, but McHugh and Foster (1996) suggested that sulfur applications on cabbage foliage caused a significant decrease in DBM oviposition. However, besides sulfur or nitrogen on their own, nitrogen/ sulfur ratio has been shown to affect GS content and subsequently plant-insect interactions (Badenes-Prez et al. 2010). Plant quality tends to decrease with leaf age (Travers-Martin and Müller 2008), and this decline in quality can affect insect fitness through different ways, but continuous usage of fertilizers keeps nutritious elements at accessible levels for insect, which is one of the aspects of anthropogenic influences on the ecosystems, and the outcome can divert us from improving our understanding of reality. However, in some ecosystems nutrient enrichments increased primary consumer production but not predator's counterpoint (Davis et al. 2010) and can cause instability in a system (Roy and Chattopadhyay 2007).

It is well known that plant allelochemicals can affect the behavior and performance of parasitoids (Harvey et al. 2005), but scenarios are different depending on plant condition during experiments. When plants are living, they can interact with herbivores, and it will be expected that this interaction differs throughout an herbivores feeding window, as both interacting species are varying in performance. But when leaves are excised from plants, their interactions with herbivores may be disrupted, as the leaves are just dead materials with the same quality of their plant at cutting time. In this case, the quality of the host plant is fixed during herbivore feeding time and the amount of the food will only decrease. In such studies that used excised leaves as host plant material, the herbivores do not encounter with living plant reactions (to herbivore feeding activity) and so are expected to suffer less from their host defense strategies. But the effect on parasitoid performance is less well predicted, as their host (herbivore) shows two faces, one as a high-quality host and another as well defended against natural enemies. However, results of such studies should be interpreted with caution.

Acknowledgments The work is a part of $\mathrm{PhD}$ dissertation of the first author that was funded by Tarbiat Modares University and was partly supported by a grant from the Center of Excellence for Integrated Pests and Diseases Management of Oil Crops of Iran. 


\section{References}

Agrawal AA (2004) Plant defense and density dependence in the population growth of herbivores. Am Nat 164:113-120

Aqueel MA, Leather SR (2011) Effect of nitrogen fertilizer on the growth and survival of Rhopalosiphum padi (L.) and Sitobion avenae (F.) (Homoptera: Aphididae) on different wheat cultivars. Crop Protect 30:216-221

Awmack CS, Leather SR (2002) Host plant quality and fecundity in herbivorous insects. Annu Rev Entomol 47:817-844

Badenes-Perez FR, Reichelt M, Heckel DG (2010) Can sulfur fertilisation improve the effectiveness of trap crops for diamondback moth, Plutella xylostella (L.) (Lepidoptera: Plutellidae)? Pest Manag Sci 66:832-838

Barbosa P, Gross P, Kemper J (1991) Influence of plant allelochemicals on the tobacco hornworm and its parasitoid, Cotesia congregata. Ecology 72:1567-1575

Benrey B et al (1998) The Effects of domestication of Brassica and Phaseolus on the interaction between phytophagous insects and parasitoids. Biol Control 11:130-140

Bryman A, Cramer D (2002) Quantitative data analysis with SPSS release 10 for windows (A guide for social scientists). Taylor \& Francis Inc., London

Campbell BC, Duffey SS (1979) Tomatine and parasitic wasps Hyposoter exiguae: potential incompatibility of plant antibiosis with biological control of the tomato pest, Heliothis zea. Science 205:700-702

Carey JR (2001) Insect biodemography. Annu Rev Entomol 46:79-110

Coley PD, Bateman M, Kursar T (2006) The effects of plant quality on caterpillar growth and defense against natural enemies. Oikos 115:219-228

Davis JM et al (2010) Long-term nutrient enrichment decouples predator and prey production. Proc Natl Acad Sci 107:121-126

De Kraker J, Rabbinge R, Van Huis A et al (2000) Impact of nitrogenousfertilization on the population dynamics and natural control of rice leaffolders (Lep.: Pyralidae). Int J Pest Manage 46:225-235

Deevey ES (1947) Life tables for natural populations of animals. Q Rev Biol 22:283-314

Eigenbrode SD et al (1996) Mobility of three generalist predators is greater on cabbage with glossy leaf wax than on cabbage with a wax bloom. Entomol Exp Appl 81:335-343

Gols $\mathrm{R}$ et al (2008a) Performance of generalist and specialist herbivores and their endoparasitoids differs on cultivated and wild Brassica populations. J Chem Ecol 34:132-143

Gols R et al (2008b) The effect of direct and indirect defenses in two wild brassicaceous plant species on a specialist herbivore and its gregarious endoparasitoid. Entomol Exp Appl 128:99-108

Gols R et al (2009) Are population differences in plant quality reflected in the preference and performance of two endoparasitoid wasps? Oikos 118:733-742

Gunasena GH et al (1990) Effects of nicotine on growth, development, and survival of the tobacco budworm (Lepidoptera: Noctuidae) and the parasitoid Campoletis sonorensis (Hymenoptera: Ichneumonidae). J Econ Entomol 83:1777-1782

Gupta PD, Thorsteinson AJ (1960) Food plant relationships of the diamond-back moth (Plutella maculipennis (Curt.)). Entomol Exp Appl 3:305-314

Harvey JA (2005) Factors affecting the evolution of development strategies in parasitoid wasps: the importance of functional constraints and incorporating complexity. Entomol Exp Appl $117: 1-13$

Harvey JA, Van Dam NM, Gols R (2003) Interactions over four trophic levels: food plant quality affects development of a hyperparasitoid as mediated through a herbivore and its primary parasitoid. J Anim Ecol 72:520-531

Harvey JA et al (2005) Effects of quantitative variation in allelochemicals in Plantago lanceolata on development of a generalist and a specialist herbivore and their endoparasitoids. J Chem Ecol 31:287-302

Harvey JA et al (2007) Effects of dietary nicotine on the development of an insect herbivore, its parasitoid and secondary hyperparasitoid over four trophic levels. Ecol Entomol 32:15-23

Hunter MD (2003) Effects of plant quality on the population ecology of parasitoids. Agric For Entomol 5:1-8

Hunter MD, Price PW (1992) Playing chutes and ladders: heterogeneity and the relative roles of bottom-up and top-down forces in natural communities. Ecology 73:724-732

Johnson MTJ (2008) Bottom-up effects of plant genotype on aphids, ants, and predators. Ecology 89:145-154

Johnson ML, Zalucki MP (2007) Feeding and foraging behaviour of a generalist caterpillar: are third instars just bigger versions of firsts? Bull Entomol Res 97:81-89

Karla YP (1998) Reference methods for plant analysis. Soil and Plant Analysis Council, Inc. CRC Press, Boca Raton

Karowe DN, Martin MM (1989) The effects of quantity and quality of diet nitrogen on the growth, efficiency of food utilization, nitrogen budget, and metabolic rate of fifth-instar Spodoptera eridania larvae (Lepidoptera: Noctuidae). J Insect Physiol 35:699-708

Kogan M, Cope D (1974) Feeding and nutrition of insects associated with soybeans. 3. Food intake, utilization, and growth in the soybean looper, Pseudoplusia includence. Ann Entomol Soc Am 66:67-72

Kos M et al (2011) Prey-mediated effects of glucosinolates on aphid predators. Ecol Entomol 36:377-388

Li Q et al (2000) Feeding and growth of Plutella xylostella and Spodoptera eridania on Brassica juncea with varying glucosinolate concentrations and myrosinase activities. J Chem Ecol 26:2401-2419

Lill JT, Marquis RJ, Ricklefs RE (2002) Host plants influence parasitism of forest caterpillars. Nature 417:170-173

Loader C, Damman H (1991) Nitrogen content of food plants and vulnerability of Pieris rapae to natural enemies. Ecology $72: 1586-1590$

Lohr B et al (2007) Impact of an exotic parasitoid on Plutella xylostella (Lepidoptera: Plutellidae) population dynamics, damage and indigenous natural enemies in Kenya. Bull Entomol Res 97:337-350

Lou Y, Baldwin IT (2004) Nitrogen supply influences herbivoreinduced direct and indirect defenses and transcriptional responses in Nicotiana attenuata. Plant Physiol 135:496-506

Maia AHN et al (2000) Statistical inference on associated fertility life table parameters using jackknife technique: computational aspects. J Econ Entomol 93:511-518

Mattson WJ (1980) Herbivory in relation to plant nitrogen content. Annu Rev Ecol Syst 11:119-161

McHugh JJ Jr, Foster RE (1996) The influence of macronutrient fertilization on diamondback moth infestation on head cabbage. J Veg Crop Prod 1:81-95

Meyer JS et al (1986) Estimating uncertainly in population growth rates: jackknife vs. bootstrap techniques. Ecology 67:1156-1166

Moreau J et al (2009) Host plant cultivar of the grapevine moth Lobesia botrana affects the life history traits of an egg parasitoid. Biol Control 50:117-122

Ode PJ (2006) Plant chemistry and natural enemy fitness: effects on herbivore and natural enemy interactions. Annu Rev Entomol $51: 163-185$ 
Ode PJ et al (2004) Host plant, host plant chemistry and the polyembryonic parasitoid Copidosoma sosares: indirect effects in a tritrophic interaction. Oikos 104:388-400

Poelman EH et al (2009) Chemical diversity in Brassica oleracea affects biodiversity of insect herbivores. Ecology 90:1863-1877

Price PW et al (1980) Interactions among three trophic levels: influence of plants on interactions between insect herbivores and natural enemies. Annu Rev Ecol Syst 11:41-65

Prudic K, Oliver J, Bowers M (2005) Soil nutrient effects on oviposition preference, larval performance, and chemical defense of a specialist insect herbivore. Oecologia 143:578-587

Raubenheimer D, Simpson SJ (1997) Integrative models of nutrient balancing: application to insects and vertebrates. Nutr Res Rev 10:151-179

Rosner B (2000) Fundamentals of biostatistics. Duxbury Pres, North Scituate

Roy S, Chattopadhyay J (2007) Enrichment and stability: a phenomenological coupling of energy value and carrying capacity. BioSyst 90:371-378

Sarfraz M, Dosdall LM, Keddie BA (2009) Host plant nutritional quality affects the performance of the parasitoid Diadegma insulare. Biol Control 51:34-41

SAS (2003) SAS statistics and graphics guide, release 9.1. SAS Institute, Cary

Scriber JM (1979) The effects of sequentially switching food plants upon biomass and nitrogen utilization by polyphagous and Stenophagous papilio larvae. Entomol Exp Appl 25:203-215

Scriber JM (1981) Sequential diets, metabolic costs, and growth of Spodoptera eridania (Lepidoptera: Noctuidae) Feeding upon dill, lima bean, and cabbage. Oecologia 51:175-180

Smith DS, Northcott FE (1951) The effects on the grasshopper, Melanoplus mexicanus mexicanus (Sauss.) (Orthoptera: Acrididae), of varying the nitrogen content in its food plant. Can J Zool 29:297-304
Soler R et al (2005) Root herbivore effects on above-ground herbivore, parasitoid and hyperparasitoid performance via changes in plant quality. J Anim Ecol 74:1121-1130

Soler R et al (2007) Impact of foliar herbivory on the development of a root-feeding insect and its parasitoid. Oecologia 152:257-264

Soufbaf M et al (2010a) Bottom-up effect of different host plants on Plutella xylostella (Lepidoptera: Plutellidae): a life-table study on canola. J Econ Entomol 103:2019-2027

Soufbaf M et al (2010b) Development and age-specific mortality of diamondback moth on Brassica host plants: pattern and causes of mortality under laboratory conditions. Ann Entomol Soc Am 103:574-579

SPSS (2008) SPSS base 16.0.2 for windows user's guide. SPSS Inc.

Stiling P, Moon DC (2005) Quality or quantity: the direct and indirect effects of host plants on herbivores and their natural enemies. Oecologia 142:413-420

Talekar NS, Shelton AM (1993) Biology, ecology, and management of the diamondback moth. Annu Rev Entomol 38:275-301

Travers-Martin N, Müller C (2008) Matching plant defence syndromes with performance and preference of a specialist herbivore. Funct Ecol 22:1033-1043

Walker M, Hartley SE, Jones TH (2008) The relative importance of resources and natural enemies in determining herbivore abundance: thistles, tephritids and parasitoids. J Animal Ecol 77:1063-1071

White TCR (1984) The abundance of invertebrate herbivores in relation to the availability of nitrogen in stressed food plants. Oecologia 63:90-105

Winter TR, Rostás M (2010) Nitrogen deficiency affects bottom-up cascade without disrupting indirect plant defense. J Chem Ecol 36:642-651

Yang JC, Chu YI, Talekar NS (1993) Biological studies of Diadegma semiclausum (Hym., Ichneumonidae), a parasite of diamondback moth. Entomophaga 38:579-586 